\title{
Redox control on sulfur mobility in the magmatic-hydrothermal ore- forming environment
}

\author{
ZOLTAN ZAJACZ ${ }^{1}$, ALEXANDRA TSAY ${ }^{1}$ AND NUUR \\ GHAZALI
}

${ }^{1}$ Department of Earth Sciences, University of Geneva, Rue des Maraichers 13, 1205 Geneva, Switzerland,

zoltan.zajacz@unige.ch

Efficient porphyry-type ore genesis requires the simultaneous introduction of ore metals and sulfur into hydrothermal systems associated with crystallizing and degassing magma bodies in the Earth's upper crust. The way $\mathrm{S}$ is distributed between the silicate melt, magmatic sulfide or anhydrite and primary magmatic fluid phases, as well as between brine and vapor upon fluid boiling determines its ultimate availability for ore precipitation in various parts of the hydrothermal system.

We combined newly-constructed fluid/silicate melt partitioning models for $\mathrm{S}$ with published magmatic sulfide and anhydrite saturation models to assess the efficiency of S extraction by fluids during the crystallization of upper crustal magma reservoirs. The results show that sulfide destruction upon magma degassing, and thus $\mathrm{S}$ extraction from the magma are efficient in reduced systems under most plausible conditions, whereas magmatic anhydrite may serve as an efficient $\mathrm{S}$ trap in oxidized systems. In oxidized magmas, higher than average initial water concentrations, and in particular, shallow emplacement depth will favor effective S transfer to the hydrothermal system.

To address the redox-dependent behavior of $\mathrm{S}$ upon subsequent fluid boiling, we conducted oxygen fugacity $\left(f \mathrm{O}_{2}\right)$ -series brine/vapor partitioning experiments using the synthetic fluid inclusion (SFI) technique. The quartz host of the SFI was fractured in situ during the experiments after the fluid attained redox equilibrium. Sulfur concentrations in the brine and vapor inclusions were determined by Laser Ablation Inductively Coupled Plasma Mass Spectrometry (LA-ICP-MS). The results show that the partitioning of S into the brine phase increases greatly with increasing $f \mathrm{O}_{2}$, and in oxidized systems, with increasing alkali metal/S ratios. For example, at a brine/vapor density contrast of about 3.7, the typical brine/vapor partition coefficient of reduced $\mathrm{S}\left(\mathrm{Ds}^{\mathrm{b} / \mathrm{v}}\right)$ is $0.19 \pm 0.07(1 \sigma)$, whereas at oxidized conditions typical of porphyry ore-forming systems, $\mathrm{Ds}^{\mathrm{b} / \mathrm{v}}$ values as high as $22 \pm 4$ can be attained. Due to their ability to simultaneously collect $\mathrm{S}$ and ore metals, brines can be effective ore-forming fluids without external $\mathrm{S}$ source if a part of their $\mathrm{S}^{6+}$ budget can be reduced to facilitate metal sulfide precipitation. 